\title{
CRIMINAL LABELLING, PUBLICITY, AND PUNISHMENT
}

(Accepted 20 September 2016)

\begin{abstract}
This paper considers whether publicizing criminal labels is justified as a form of punishment. It begins by arguing that making criminal labels public is inevitably stigmatizing and that stigmatization is not, as is often implied, a defining aspect of censure, but needs independent justification. It argues that justifying grounds for public criminal labelling cannot be found in either the communicative account of punishment or deterrence theory. Rather, public criminal labelling should be understood as undermining of both the communicative and the deterrent functions of punishment. Recent empirical work is drawn upon to support the claims about public criminal labelling and deterrence.
\end{abstract}

\section{INTRODUCTION}

Being implicated in criminal behaviour is often followed by some form of public criminal labelling. Criminal records, sex offender and domestic violence registers, conspicuous clothing for offenders carrying out community sentences, are all examples of criminal labels, understood here as officially recorded expressions of judgements about the criminality of an individual. The visibility of criminal labels varies widely both within and between jurisdictions. For example, in a number of European countries, state authorities conceal the identity of those charged and convicted with crimes, though some public interest exceptions apply. ${ }^{1}$ In contrast, in the USA state authorities broadcast, via publicly searchable databases on the Internet, the identities of people convicted, charged, or even merely arrested in connection with crimes. ${ }^{2}$ In the UK, some offenders serving community service sentences are compelled to wear high-

\footnotetext{
${ }^{1}$ Jacobs and Larrauri, 'Are criminal convictions a public matter? The USA and Spain' Punishment and Society, 14(1), 2012.

${ }^{2}$ Ibid.
} 
visibility orange vests while they work, thereby alerting their status to members of the public, ${ }^{3}$ and some preventive criminal designations, such as Anti Social Behaviour Orders ('ASBOs') and prevention orders, are routinely publicised by police on posters and in local media, even when they pertain to children. At the same time, however, in most countries the identities of minors charged or convicted with crimes are concealed until they reach the age of eighteen. As this diversity suggests, at least on the face of things no single rationale for applying and publicising criminal labels can explain current practice.

When is a state justified in attaching a criminal label to someone and what kind of publicity should that label be given? Recent critical discussions of criminal labelling practices largely ignore questions regarding the proper scope and nature of the publicity given to criminal labels. They focus instead on the necessary and sufficient conditions for applying such labels in the first place. In particular, they seem preoccupied with the question of whether labelling can ever be justified for those whose criminal guilt has not been legally proven. The reason most often put forward for this preoccupation is that labelling people as criminals stigmatises them as such. Criminal stigmatisation, it is argued, is a burden, which should only be suffered by those whose criminal guilt has been proven to a sufficiently high standard. ${ }^{4}$

It is sometimes claimed, but more often an underlying assumption of these discussions, that public labelling in response to proven criminal guilt - e.g. of criminal convictions - is permitted, at least in part, because people who commit crimes deserve to be labelled publicly as criminals. ${ }^{5}$ Public criminal labelling is thus implicitly conceptualised as a legitimate form of, or aspect of punishment, even when it is not defined as such in substantive criminal law. And it is taken as given that labelling should, like any other kind of de facto punishment, be reserved for the legally guilty; practices that attach criminal labels to those not proven guilty of crimes are thought to risk punishing the innocent and thus undermining or violating the

\footnotetext{
${ }^{3}$ See UK government webpage 'Community Service': https: / /www.gov.uk/ community-sentences/ community-payback.

${ }^{4}$ Campbell, L. 'Criminal labels, the European Convention on Human Rights, and the presumption of innocence', Modern Law Review, 76(4), 2013. Stanton-Ife 'Strict Liability: Stigma and Regret' Oxford Journal of Legal Studies, 27(1), 2007.

${ }^{5}$ Stanton-Ife (2007, p. 153).
} 
presumption of innocence. ${ }^{6}$ For this reason, public criminal labelling is seen as unproblematic in principle for convicted offenders, but as prima facie suspect for those subject to preventive measures such as ASBOs.

This account of the conditions for just criminal labelling is problematic, for at least two reasons. The first relates to its assumption that questions about the necessary and sufficient conditions for justified criminal labelling can be answered without consideration of the publicity given to such labels. I share - and in this paper put forward arguments in support of - the view that criminal labelling is in practice stigmatising and that stigma is a burden that needs justification. But it seems to me that the extent to which criminal stigmatisation of a specific individual occurs depends, at least in part, on the extent to which the criminal label attached to them is visible to others. In other words, publicity is not a necessary feature of criminal labelling, but it is a necessary condition of criminal stigmatisation. So we have to first justify the legitimacy of public criminal labelling as a form of punishment, before we can conclude that it should only be applied to the guilty. But - and here we come to the second problem, which is also the main focus of this paper - I am sceptical that a justification for public labelling can in fact be found in the need to punish. And if public labelling is not justified as punishment, then questions about when it is justified are less easy to resolve by reference to the existence of legal proof of guilt than some legal theorists suppose.

In what follows, I sketch out and then highlight difficulties with two defences of public criminal labelling as punishment: the communicative defence and the deterrence defence. The communicative account of punishment is one of the most influential in scholarly circles today and can offer probably the most convincing defence of public labelling. Deterrence continues to be the criminal justice aim most frequently cited by police and policy makers in defence of criminal labelling practices. Neither the communicative nor the

${ }^{6}$ Ball, D.W. 'The civil case at the heart of criminal procedure: in re Winship, stigma and the civilcriminal distinction', American Journal of Criminal Law 38(2), 2011. Also Campbell, who argues that the presumption of innocence can be interpreted 'as conveying to the citizenry that an individual may be depicted and censured openly as criminal only with proof to the requisite level.' As I note later, this merely begs the question of whether punishment requires publicity of criminal labels or not. See Campbell (2013, p. 690). 
deterrence case for public labelling of criminals has as yet been subject to systematic critical scrutiny.

Though recent years have seen an increase in the prevalence of the public naming-and-shaming of perceived wrongdoers, in particular online, and though the justice of shaming sanctions is a live debate amongst moral and legal theorists, ${ }^{7}$ I do not consider in this paper whether public labelling is justified in virtue of the shame it induces in criminals. This is partly because shaming sanctions are often justified in virtue of their deterrence value, which is already addressed below, and partly because I agree with those scholars who find it difficult to accept that suffering for suffering's sake can be a legitimate aim of criminal punishment.

Neither do I consider here whether making criminal labels public might be justified for non-punitive reasons. Rather, I leave open the question whether publicity might be justified by appeal to the need for transparency and openness in criminal justice; the right of people to know about the criminality of others; the need to reduce the risk posed by ex-offenders to the public; or the potential reassurance publicity might offer the public, amongst other things. These nonpunitive justifications certainly deserve sustained consideration. I think such consideration will be easier to achieve once we are clearer about whether publicity serves what is arguably the fundamental function of criminal justice, namely to punish the guilty.

However, the arguments put forward here are relevant to considerations of whether publicity of criminal labels is justified as a byproduct - or 'collateral consequence' - of punishment. First, they suggest that punishment does not require publicity of labels, and therefore that public labelling is not a necessary by-product of punishment. Second, they claim that the harms of public labelling raise issues of fairness and proportionality; as has been argued extensively in the context of debates about war, fairness and proportionality considerations apply not only to actions and policies but also to the byproducts thereof. ${ }^{8}$ These arguments are relevant to government actors - typically policy-makers and legislators - responsible for devising

\footnotetext{
${ }^{7}$ Nussbaum, Martha, Hiding from Humanity: Shame, Disgust and the Law. Princeton University Press, 2004; Kahan DM, 'What's really wrong with shaming sanctions' Texas Law Review 84(7), 2006: 2075 2097; Arneson, R. 'Shame stigma and disgust in the decent society', Journal of Ethics, 11(1) 2007: 31-63.

${ }^{8}$ For a seminal discussion of this issue in the context of just war theory see Walzer, Michael, Just and Unjust Wars, New York: Basic Books 1997, pp. 151-159.
} 
punishments and thus for deciding whether and to what extent they will include an element of public labelling. They are also relevant to members of the judiciary when and to the extent that they have the discretion to choose between the infliction of punishments involving labelling and punishments that do not. With respect to much current practice in the UK, including the imposition of ASBOs and community service uniforms, such discretion is not afforded to judges; more discretion is afforded to judges in some US states.

The paper is structured as follows. I begin by arguing that stigmatisation and the public labelling that triggers it are not essential to punishment, as some theorists imply, but rather must be defended by appeal to their contribution to one or more of the justifying functions of punishment. I then consider the communicative and the deterrence functions in turn. First, I argue that the communicative justification fails because it delegates the right to punish to individual citizens. At best, this places unrealistic and unreasonable demands on individuals to punish. At worst, it leads to disproportionality in punishment. I argue that the disproportionality it leads to is more difficult to justify than the disproportionality that currently results from standardised punishments like incarceration, because it is the product of unfairness and discrimination towards those labelled. Finally, against the deterrence-based justification for public labelling, I draw on recent empirical work in labelling theory to argue that labelling aggravates recidivism and thus fails to deter the group most likely to commit crime, namely ex-offenders.

\section{UNTANGLING CRIMINAL LABELLING, STIGMATISATION, AND CENSURE}

Before examining the communicative and deterrence potential of public labelling, I want to consider the claim that stigmatisation is a defining feature of criminal punishment, because this claim implies that, irrespective of the specific theory of punishment one subscribes to, wherever punishment is the appropriate reaction to an act, so is criminal stigmatisation. If this is correct, then the fact that labelling someone as criminal stigmatises them is by itself no reason not to label them, if it is morally legitimate to punish them. I argue that this view mistakenly conflates censure, which is indeed a defining feature of punishment, with criminal stigmatisation, which is not. If I am 
correct, then the fact that punishment is the correct response to an act is not sufficient reason to publicly label and thus stigmatise someone as criminal.

Stigmatisation involves the process of marking someone out in some visible and identifiable way as having a characteristic that is deeply discrediting. ${ }^{9}$ The more visible and identifying the mark, the more it dominates other facts about the person, and the more discrediting it is, the more stigmatizing it is. ${ }^{10}$ Most acts of marking out that are stigmatizing are in fact motivated by negative reactions (like public disapproval of crime) to some actual or perceived quality of the individual, but negative motivations are not a necessary feature of stigmatization: an act of marking out may be intended to honour but may in practice have the effect of degrading. In contrast, negative reactions to a mark are necessary for stigmatization. These reactions are what make stigmatization properly understood as burdensome. As sociologists have argued, stigmatization results in status loss, discrimination and disadvantage, as the stigmatized individual is both alienated and excluded from activities and opportunities open to the non-stigmatised. ${ }^{11}$ However, it seems to me that the core or essential burden of stigmatization, conceptually speaking, is status loss, from which discrimination and disadvantage flow. ${ }^{12}$

The extent to which criminal stigmatisation actually occurs as a result of the infliction of a criminal label depends on how individuals in different relationships to the person labelled interpret and react to that label. The infliction of an identical criminal label on two individuals can lead to stigmatisation of one but not of another, depending on the values of the relevant peer group and the social status of the individual labelled. For example, positions of power occupied by some people in society can insulate them from at least

\footnotetext{
${ }^{9}$ Goffman, Ervin. Stigma: Notes On The Management Of Spoiled Identity. Englewood Cliffs, N.J.: Prentice-Hall (1963, p. 3).

${ }^{10}$ See Braithwaite 1989 for a justification of the criterion of dominance over other features of a person.

${ }^{11}$ Link and Phelan. 'Conceptualising Stigma', Annual Review of Sociology, 27, 2001.

${ }^{12}$ While status loss is inherent to stigmatization, it can occur without stigmatization. Jean Hampton puts forward a theory of retributive punishment as an infliction of status loss on the offender designed to deny the claim to superiority implicit in the criminal act and thus to vindicate the victim's equal worth (Murphy and Hampton 1988, pp. 125-128). Status loss in Hampton occurs as a result of the mastery of another, mastery that may include but is certainly not limited to the making of a statusdegrading mark.
} 
some of the status loss and disadvantage that would be likely to result for others similarly labelled ${ }^{13}$ while others who identify with criminal peers may find their status thus enhanced. ${ }^{14}$ It also depends on how public the label is, meaning in part how prominent it is to those to whom it is visible and in part how many people the label is visible to. Other things being equal, the greater the number of people to whom the label is visible, the greater the number of reactions to it, the greater the loss of status. At the same time, a label that is impossible to ignore, like the orange boiler suits worn to carry out community service penalties, is more likely to provoke negative reaction than one people can choose to pretend not to have noticed.

Some legal theorists claim or imply in their writings that stigma overlaps or is synonymous with censure, which is itself a defining feature of punishment (coercion or 'hard treatment', being the other). ${ }^{15}$ Thus John Kleinig states that 'punishment involves a stigmatizing condemnation of the punished...'16; and Andrew Taslitz claims that 'disesteem-imposition, even if not phrased quite this way, is a clear goal of our criminal justice system. The system assumes that conviction carries stigma with it and that the degrees of, and actual imposition of, various sentences reflect various degrees of disesteem. ${ }^{, 17}$

This conflation of stigma and censure is problematic because it leaves out at least two essential aspects of the former not shared by the latter: marking out and visibility. Unlike stigmatisation, criminal censure need not involve a process of marking out visibly. ${ }^{18}$ This fact is concealed by talk about labelling that implies that publicity is

\footnotetext{
13 Ibid.

${ }^{14}$ Walker, N. Punishment, Danger, and Stigma: The Morality of Criminal Justice, Oxford University Press, 1980, pp. 102-103. Differences between the extent to which different individuals experience an identical criminal label as stigmatising seems likely to vary relative to the extent to which: the labelled individual identifies with the disapproving group; their sense of status is determined by their position in relation to that group; they actually aspire to the goals in relation to whose attainment they are now at a disadvantage.

${ }^{15}$ Husak (2010) The Philosophy of Criminal Law: Selected Essays. New York: Oxford University Press.Ashworth and Zedner, Preventive Justice, Oxford Uni Press, 2014.

${ }^{16}$ Kleinig, John. "The hardness of hard treatment." Fundamentals of Sentencing Theory (1998) p. 273.

17 Taslitz, 'Judging Jena's DNA: The Prosecutor and Racial Esteem' Harvard Civil Rights and Civil Liberties Review, 44, 2009, pp. 313, 414.

${ }^{18}$ The question of whether stigmatization can occur without publicity was raised in a juridical context in relation to the case of Marper, where the referral by the Chamber of the ECtHR to the criminal stigmatization of unconvicted individuals whose DNA data was nevertheless retained by police was challenged by the UK government, which countered that stigma could not arise in the absence of a public articulation of suspicion ( $\mathrm{v}$ Chief Constable of South Yorkshire Police, ex parte LS and Marper (2004) UKHL 94-122)
} 
integral to it. For example, Campbell describes criminal labelling as involving people being 'depicted and censured openly as criminal' without explaining why openness or depictions should be considered so central. ${ }^{19}$ Yet censure could - and indeed in many jurisdictions often does - happen in closed proceedings where the official declaration of criminal guilt is witnessed by very few people and where the offender's anonymity is guaranteed. Even in a system that, like the UK's, favours publicity, some categories of trials take place in closed proceedings. This is the case, for example, with some proceedings dealing with terrorism offences, and with all proceedings in family courts. The fact that declarations of guilt in such cases are made in closed proceedings does not by itself render the declaration any less condemnatory, nor necessarily any less expressive of public disapproval (at least in the sense that 'public' can be taken to mean disapproval expressed in the name of the public via legitimate democratic mechanisms). ${ }^{20}$ In other words, unlike stigmatization, which - other things being equal - increases with the publicity given to a stigmatic label, censure need be no less censorious if it is delivered in relative private. $^{21}$

This should not be taken to mean that public disapproval expressed in response to criminal labelling is not censorious; only that it is not necessary to the specific kind of censure that is itself a defining aspect of punishment. Those who define the expression or direction of public disapproval at an individual through criminal censure as stigmatizing may be confusing the attitudes motivating the imposition of criminal censure with those provoked by it. It is the public disapproval expressed by criminalization of an act that makes restrictions of liberty condemnatory and thus distinguishes them from other, non-punitive restrictions. The public disapproval that may be triggered by the criminal label imposed in response to censure is related but distinct.

\footnotetext{
${ }^{19}$ Campbell (2013, p. 690), my italics.

${ }^{20}$ This stands in contrast to the claims of some theorists that, in order to achieve its aims, censure must also be communicated to the public. For example, Ashworth and Zedner have recently claimed that it is 'inherent' to the exercise of censure that it be communicated 'to the victim (if any) and to the public at large' (Ashworth and Zedner 2014, p. 14).

${ }^{21}$ There is no inconsistency between this claim and the observation, made helpfully by an anonymous reviewer of this paper, that being censured by more people may imply more censure. This is because the claim (and indeed the issue at hand) regards the impact on censure of its being done in public. It does not regard the related but distinct issue of the impact on censure of greater participation in the act of censure.
} 
One source of the confusion detected here may be unconscious slippage between the censure and stigmatisation involved in the criminalisation of an act (the result of a legislative process), and the censure and stigmatisation involved in the criminalisation of a person (the result of a judicial or quasi-judicial process). Criminalisation marks an act out as morally condemnable, and in that sense it attaches stigma to that act. It is also censorious to the extent that it directs censure towards those as-yet-unidentified individuals who commit the criminal act. Is stigmatisation avoidable, given that legislating to make some activity criminal invariably involves stigmatising those who engage in it? This, former kind of stigmatisation is not avoidable; but neither is it the kind of stigmatisation that is potentially harmful in the ways described above. Rather, it is an abstract kind of stigmatisation, which necessarily accompanies criminalisation but is (theoretically at least) proportionate to the seriousness of the crime, and is therefore unresponsive to the contingent factors that determine stigmatisation (like whether or not in practice other individuals become aware of and react negatively to the label).

Thus far I have tried to show that neither public labelling nor stigmatisation are essential to punishment. If this is correct, then the question of whether labelling is justified in any particular case cannot be determined by reference solely to the permissibility of punishing in that case. In the following two sections, I consider the possibility that public criminal labelling fulfils one or more of the justifying functions of punishment and that this provides a prima facie argument in favour of it.

The theorists mentioned in the introduction to this paper are right to point out that labelling as criminal someone who has not been proven to be one is unjust. But it seems less obvious that giving publicity to criminal labels attached to those who have been proven guilty should be considered unproblematic. Indeed, the fact that people convicted of crimes are not routinely required to wear badges publicising their wrongdoing suggests that there are reasons operative in criminal justice systems that count against public criminal labels, at least highly conspicuous ones. 
In his 1986 book, in which he lays the ground for his communicative theory of punishment, Anthony Duff considers the merits of just this kind of labelling-as-punishment, as an alternative to incarceration or other forms of hard treatment. ${ }^{22} \mathrm{He}$ suggests that the reasons 'symbolic ${ }^{\text {,23 }}$ forms of punishment, such as criminal badges, are not considered appropriate by either consequentialist or retributivist theories, relate to the inevitable inconsistency and arbitrariness with which the public will express their disapproval of those labels means 'they will not distribute punishments equitably, or ensure that offenders receive the kind and degree of punishment they deserve'. ${ }^{24}$ However, he implies, if the problem of proportionality and coordination could be resolved, then public criminal labelling as punishment has many advantages from a communicative perspective.

Duff s suggestions about the potential costs and benefits of public criminal labelling as punishment are worth contemplating, because they invite us to think about labelling in isolation from the other, formal restrictions it often accompanies. Doing so helps to fix attention on the rationale for and reasons against labelling as punishment. And, as I will argue below, these reasons apply, albeit to varying degrees, to contemporary criminal labelling practices too.

If Duff is correct to claim that conspicuous criminal labelling would fulfil effectively the communicative function of punishment, and that its only downside would be potential disproportionality, then perhaps the arguments in its favour are stronger than he thinks. After all, disproportionality is a problem that arises in connection with all kinds of punishments. ${ }^{25}$ And the communication of censure is acknowledged as an important, if not vital function of punishment, even by those who reject claims that communication can be a complete theory of punishment. ${ }^{26}$ If we can preserve the communicative potential of public labelling while reducing the risk of dis-

\footnotetext{
${ }^{22}$ Duff, Trials and Punishments, London: Cambridge University Press, 1986.

${ }^{23}$ While Duff and others refer to this kind of public criminal labelling as a purely 'symbolic' penalty, thus implying that there is no hard treatment involved (and therefore none that must be justified), this is misleading. The state's actions in labelling people publicly amount to hard treatment, because forcing people to wear badges is a form of coercion.

${ }^{24}$ Duff (1986, p. 149).

${ }^{25}$ Ryberg, J. The Ethics of Proportionate Punishment: A Critical Investigation. Kluwer (2004); Kolber 'Unintentional punishment' Legal Theory, 18 (2012).

${ }^{26}$ Tadros, The Ends of Harm: The Moral Foundations of the Criminal Law, Oxford University Press, (2011), p. 91.
} 
proportionality, then we may appear to have a strong case for the justice of labelling-as-punishment.

I think that such a case is in fact difficult to make, and in this section I explain why. I begin by acknowledging the communicative potential of conspicuous criminal labelling as punishment. Then I put forward some reasons for thinking that it is unlikely ever to be realised in practice and argue that this would continue to be true even in a society in which most people subscribe to Duff s communicative theory of punishment. Specifically, I argue that public criminal labelling is stigmatising in ways that frustrate the kind of communication justified by Duffs theory. In addition, as Duff and others note, it leads to inevitable disproportionality. I argue that the disproportionality it leads to is indicative of unfairness and discrimination towards those thus criminalised amongst other things. I suggest that both of those problems arise primarily because conspicuous criminal labelling inverts the norm common to - dare I say defining of - liberal societies, that punishment is something that should be carried out by the state on behalf of citizens, and not vice versa. ${ }^{27}$

\section{COMMUNICATIVE THEORY AND THE BENEFITS OF PUBLIC CRIMINAL LABELLING AS PUNISHMENT}

Let us begin by describing what has become known as the communicative function of punishment. The communicative account of punishment states, roughly, that the primary aim of punishment should be to communicate public disapproval of the crime to the offender in such a way as to persuade them, by appeal to moral reasons, to repent. ${ }^{28}$ According to communicative theory, both censure and hard treatment communicate disapproval and hard treatment is also a means by which offenders can do penance and repent, in something like a performance of contrition. On the

\footnotetext{
${ }^{27}$ This norm is most obviously derivable from John Locke and Robert Nozick's individualist liberalism, in which the move from a state of nature to organized society involves individuals delegating their natural right to punish to the state (Locke 1689, pp. 128-130; Nozick 1974, p. 112). In contrast, Duff's communitarianism conceptualizes the right to punish as an entitlement not of individuals but of the community. Nevertheless, both theories assert that punishment for crimes is a right exercised via the legitimate institutions of the state. And both deny that citizens, collectively or as individuals, retain a right to punish that can be exercised independently of the punishing acts of the legitimate institutions of the state (Duff 2013).

${ }^{28}$ Duff (2001, pp. 81-82).
} 
communicative account, punishment is owed both to the victims of the crime and to the perpetrator, and thus punishment is a duty and not only a right. The communicative account is retributive and thus requires that some measure of proportionality be maintained between the seriousness of the crime committed and the severity of the penalty. ${ }^{29}$

Let us turn now to consider the communicative benefits of public criminal labelling. Duffs argument in favour of labelling-as-punishment via criminal badges is that, by inflicting 'a public and ... lasting reminder of the offender's guilt' it can make offenders 'face up to' and take responsibility for what they have done, which is an essential step towards repentance. ${ }^{30}$ It does indeed seem hard to dispute that being forced to reveal one's crimes to every person one comes into physical contact with would make it difficult to ignore them. The prominence given to the criminal label over other facts about oneself would also likely force one to take seriously and reflect on one's crimes, as would being faced constantly with (presumably overwhelmingly negative) public reactions to those crimes. The fact that it would remain the responsibility of the individual offender, rather than a punishing authority, to undertake reformative actions, coupled with the natural desire to demonstrate that one has taken appropriate such actions and therefore is deserving of forgiveness and redemption (e.g. by stating 'I have stopped taking drugs and here are the results of my last blood test'; 'I have taken an anger management course and here is the copy of my certificate') may also encourage individuals to take responsibility for the state of their own moral compass.

Though Duff does not himself argue thus, we can add in support of his claims that the infliction of criminal badges might further contribute to the communicative aims of punishment by enabling a better fit between crime and punishment than the inevitably standardised penalties devised by the state: Unlike those penalties, the powers of human expression enable reactions that are infinitely subtle and true to people's attitudes about a particular act of wrongdoing. In practice, these attitudes shift over time with changes in public morality. One source of poor fit between standardised

\footnotetext{
${ }^{29}$ Duff, Punishment, Communication, and Community, (2001), p.187; von Hirsch Censure and Sanctions, Oxford: Oxford University Press, 1993, chap. 2.

${ }^{30}$ Duff (1986, p. 148).
} 
penalties and crimes stems from the weak responsiveness of the former to changes in attitudes towards the latter. If one of the fundamental aims of punishment must be to express public disapproval for wrongdoing, if the justification and moral authority of a specific punishment is drawn from its effectiveness in expressing that disapproval, then who could be better placed to deliver it in a way that reflects the nature and extent of that disapproval but the public itself? And what better opportunity to express remorse and demonstrate a commitment to reform than face-to-face with the community whose norms one has flouted? Thus it might be argued that criminal badges fulfil communicative aims of punishment in a way that is both more faithful to those aims and maintains a better fit between crime and punishment better than current, state-mediated alternatives.

\section{LIMITATIONS OF LABELLING-AS-PUNISHMENT FOR THE COMMUNICATIVE THEORY}

While the potential of conspicuous labelling to facilitate communication of disapproval, rational persuasion and repentance is powerful, there are at least two sets of reasons why we should be sceptical that this potential could ever be realised in practice. The first relates to the fact most people do not share the view that just punishment means the communication of censure in the form of rational persuasion and this means that their reactions to criminal labels are unlikely to be in the communicative spirit. The second relates to the nature of the relationship between offenders and individuals qua citizens, a relationship that I argue is not a sound basis for effective intervention of the communicative kind. Taken together, these reasons make it inevitable in practice that conspicuous labelling will facilitate public reactions to criminality that both undermine the communicative function of punishment and are unfair to those labelled.

\section{THE WRONG KIND OF REACTION TO CRIMINALITY}

In most contemporary societies not everyone shares the view that punishment means rational appeal to moral reasons. What is more, in most liberal, multicultural societies, people's views about what 
just punishment consists in diverge significantly, such that people compelled to wear criminal badges would be likely to receive a variety of responses to their criminality, of which some aim to persuade, while others aim to deter, incapacitate, or even harm. Fear of abuse or even retaliatory attacks by members of the public would, especially for those convicted of offences considered deeply shameful, be well-grounded. Recorded incidents of violence against sex offenders in the USA suggest this would in some places be a very real concern. ${ }^{31}$ So too do reports in the UK about the treatment of offenders wearing high-visibility 'community payback' vests while doing community service. These chronicle offenders being shot, beaten $^{32}$ and verbally abused, prompting protests by probation officers and a refusal by some organisations offering offender work placements to use the vests. ${ }^{33}$

Positive reports of public responses to conspicuous criminal labels are not impossible to find. One notable instance involves the case of Michael Hubacek, convicted in the USA of manslaughter for a drink driving accident. Hubacek only served six months of the ten-year prison sentence he was originally given. One condition of his probation was to wear a placard once a month outside a high school stating 'I KILLED TWO PEOPLE WHILE DRUNK DRIVING' (thus in this unusual case, the public labelling was not built into the punishment via prior legislation, as it is with the high-visibility clothing for community sentences in the UK, but rather the sentencing judge used their discretion to devise a punishment based explicitly on labelling). Hubacek reports feeling positive about his labelling, to which he says ' $90 \%$ ' of people' reacted kindly, saying things such as 'God bless you' and 'Things will be okay'. ${ }^{34}$ It is reassuring to know that public criminal labelling can prompt compassion as well as abuse. But compassion is not the same as the rational persuasion by appeal to moral reasons required by the communicative theory. And, as we can see from the religious tone of

\footnotetext{
${ }^{31}$ See for example attacks on sex offenders whose personal details made public under Megan's Law in the USA reported in Levenson et al., 'Megan's law and its impact on community re-entry for sex offenders' Behavioural Sciences and the Law, 25(4) 2007.

32 'High-visibility offenders face reprisal attacks, union warns' by Alan Travis, in The Guardian Newspaper, Friday 22 Nov, 2008. At: http://www.theguardian.com/uk/2008/nov/28/communitypayback-high-visibility-vests.

${ }^{33}$ Harry Fletcher, 'NAPO warning on high visibility vests' Napo News 206. February 2009.

${ }^{34}$ Ronson, J. So You've Been Publicly Shamed. Picador: London, (2015), p. 83.
} 
one of the comments received by Hubacek, even messages of compassion will inevitably draw on members' of the public's own personal conceptions of the good. Unless people communicate using appeals to humanity or other high-level values shared by people with a range of backgrounds, it is likely that it will be articulated in terms that the offender cannot reasonably expect to share, and thus fail to resonate with that person. Having said that, if we expect people to engage in good faith with offenders, it seems unreasonable to expect them to refrain from putting forth reasons that are genuinely their own. There seems to be a tension between the desirability of the personal element for effective communication and the desirability of a more neutral, democratic perspective from which to censure.

I think this tension arises because in Duff s example, citizens are given what he calls a 'civic' duty to punish, yet without being made democratically accountable for their punishing actions. This notion of a civic duty to punish blurs the line between interpersonal duties we owe each other as members of society and the democraticallyassigned duties of those who carry out punishing functions on behalf of citizens. This blurring is problematic because it risks lending democratic authority to - and encouraging people to feel self-righteous in the expression of - their own personal reactions to criminality, whatever these might be. In most current penal systems, those who assign, and implement criminal punishments are subject to scrutiny by democratic institutions such as parliament, specialist oversight bodies, and the media. This aims to reduce the risk that the punishments that people suffer in the name of society are unfairly imposed or inflicted in ways that fail to align with the norms of society. ${ }^{35}$ In addition, expressing to offenders one's personal disgust with criminality is not permitted while one is acting as a restorative justice officer, because doing so conflicts with the aims of the job. This prescriptiveness with respect to reactions to criminality is permitted because the aim of the job is to help reform offenders, not shame them, and the officer volunteered to do it. The same cannot be said for individual citizens acting in their personal capacity, for whom prescriptiveness of this sort would be an unacceptable interference with freedom of expression. In sum, as long as people are invited to react to criminality wherever they see it they will some-

\footnotetext{
${ }^{35}$ Owen Fiss expressed worries similar to these in relation to a legal movement in 1980s USA to encourage the use of private settlements as an alternative to court hearings, see Fiss (1984, p. 1085).
} 
times react in ways that either fail to promote or actively undermine the aims of punishment as communication. Giving them a special right to do so risks encouraging these reactions to be made more stridently and even less helpfully.

A further problem would arise from people's non-punitive reactions to criminal labels. On a communicative account, explicitly punitive reactions would include people's verbal expression of disapproval as well as disapproval expressed through some action such as the temporary suspension of a contract of employment. Nonpunitive reactions to label may occur when, faced with evidence of an individual's criminality that is impossible to ignore, yet without intending to punish, people exercise their freedom of association in ways that deny that individual social benefits and exclude them from social activities in ways that are seriously detrimental to them. While I might choose to associate with someone whose criminal history I do not know, and while I might assert and indeed believe that such history would be irrelevant to my choices of association, I might find it difficult to continue in my association if that history were shoved in my face, as it were. My decision to discontinue the association might stem more from embarrassment and awkwardness or fear of what others might think than a desire to punish, but it would nevertheless cause suffering to the labelled individual. Suffering that is multiplied many times over as others react in similar ways.

Before we consider whether this suffering can be either justified or tolerated as an unfortunate by-product of just punishment, let us consider the observation that the fact that actions such as these lack punitive intent means they cannot be conceptualized, nor indeed justified, as punishment. ${ }^{36}$ As Dan Markel has pointed out, acts taken in response to crime convey a message, but are not properly understood as retributive unless that message is intelligible to the offender. ${ }^{37}$ In relation to the current discussion, being avoided, excluded, or shunned, even ruefully, carries a message of public disapproval - a message that what one did makes one an undesirable

\footnotetext{
${ }^{36}$ Markel, D., and Flanders, C. 'Bentham on Stilts: The Bare Relevance of Subjectivity to Retributive Justice' California Law Review 98, 2010. Punitive intent is part of the definition of punishment according to Hart and others. See H.L.A. Hart, Prolegomenon to the Principles of Punishment, Proceedings of the Aristotelian Society, 60(1), 1959. David Gray claims, for example, that "no theory of criminal punishment is obliged to justify... the unintended suffering that may incidentally result from punishment." Gray, 'Punishment as suffering' Vanderbilt Law Review, 63, 2010, p. 54.

${ }^{37}$ Markel, D. 'Are Shaming Punishments Beautifully Retributive?' 54 Vanderbilt Law Review, 2001, p. 2195.
} 
associate. But unless the motivations for such action are clearly signposted (as they are during court proceedings, especially sentencing) there is little difference, from the offender's perspective, between an act of exclusion driven by a desire to punish and that driven by squeamishness. As others have pointed out, this need not be taken to mean that such actions can be disregarded or discounted by theorists of punishment. Even if we were to concede that this kind of collateral harm to the offender should carry no weight on the retributive scales, and therefore may not, strictly speaking, be an issue of punitive proportionality, it must surely carry some weight in the broader criminal justice decision-making process. ${ }^{38}$ In particular, unless it can be outweighed, the extra suffering caused by nonpunitive reactions to labels can be a legitimate reason for eschewing labelling-as-punishment in favour of another form of punishment with less weighty and inevitable collateral harms, assuming such a punishment can be found.

This extra suffering is difficult to reconcile with the communicative aims of punishment, because it actively undermines them by isolating the offender from the moral community. The inevitable shrinking away from people bearing the criminal mark is by itself sufficient to isolate individuals. But fear of the public reaction to one's criminality is also a powerful incentive to withdraw voluntarily from social interaction and/ or to seek the company of those more favourably disposed to criminality. And while the removal of a criminal label could be an opportunity to celebrate reconciliation and open the door to reintegration, by then the process of exclusion and withdrawal is likely to have raised significant and lasting barriers to these aims.

\section{UNFAIRNESS AND DISPROPORTIONALITY}

In addition to failing to bring about the kind of communication that is justified on labelling-as-punishment is unfair to offenders. People considering whether to commit criminal acts should know in advance what their punishments if caught will consist in, roughly speaking. Otherwise their decision about whether to commit the crime cannot be said to be properly informed, or, it follows, autonomously taken. The unpredictability of public responses to

\footnotetext{
${ }^{38}$ Gray, Ibid. p.1630 n46.
} 
criminal labels makes them unfair as a form of punishment for at least this reason.

A further reason why unfairness would arise is that inequalities of status would come to determine those responses, thus making proportionality difficult to achieve. The concern here is that people who are equally culpable of equally serious crimes would be punished more or less severely because of the unequal and stratified character of most modern societies. People's moral judgements of and reactions to others are influenced by the social status and other attributes of those judged. For example, research shows that people's preconceptions and personal prejudices come often to influence their performance as jurors, and that juror bias is difficult to address, either by raising jurors' own awareness of it or via pre-appointment vetting schemes. ${ }^{39}$ There is no reason to believe that bias would be any less likely to influence the reactions to criminals of the general public. There is a real risk that, in our imperfect societies, the identity of the criminal rather than the nature of the crime would too often come to determine extent the nature and severity of punishment. Such a situation sits uncomfortably with well-established and widely-held intuitions about fairness and desert, in particular the intuition that when people should be punished they should be punished for what they do rather than who they are.

Earlier, I mentioned that the problem of disproportionality is one suffered by all theories of punishment. But the disproportionality just described is harder to justify or tolerate than the disproportionality that results from imposing an identical penalty on two individuals who turn out to react to it in different ways. Standardisation in criminal penalties is an attempt by legislators to prevent bias influencing sentencing; to subject sentencing to democratic oversight; and to make both potential offenders and potential victims aware of the kinds of punishment that can be expected for specific crimes. The fact that, despite these efforts, some people will suffer more from a specific punishment than others is unfortunate, but no one is thereby wronged. In contrast, people are wronged when they suffer punishments that are determined even in part by personal prejudices towards them.

\footnotetext{
${ }^{39}$ Roberts, A, '(Re)forming the Jury: Detection and Disinfection of Implicit Juror Bias', Connecticut Law Review 44(3), 2012.
} 
The problems with conspicuous labelling that I have just pointed to are not problems internal to the communicative theory. Rather, they are problems that arise mainly because not enough people actually subscribe to the communicative theory. If most people genuinely did subscribe to that theory, then the uncertainty faced by the offender, the risk and fear of insult or abuse, the parallel trepidation felt by members of the public, the resulting disproportionality and the tendency of labelling to marginalise rather than reintegrate the offender would either disappear or be reduced significantly. If this were to occur, would conspicuous criminal labelling serve well enough the communicative aims of punishment, so as to make it justified? As I will now argue, there are compelling reasons to think not.

It is pertinent to recall here that the aim of communication is to engage the offender in moral reflection and rational persuasion that will help them recognise the wrongness of their actions, repent, and seek a reconciliation with the society whose norms they have transgressed. The effectiveness of any such communication ventured by a citizen is likely to depend to some extent on their knowledge both of the particular case and of the individual in question. Without sufficient knowledge of the case, it would be all too easy for people to censure inappropriately. The detail presented at trial proceedings serves not only to promote fair verdicts but also to inform sentencing. It is hard to see how sufficient detail could be made available to the public to enable them to respond appropriately to a criminal badge.

But even if this problem were surmountable, it still seems unlikely that ordinary strangers will provide reliably the right responses to criminality. Duff speaks of 'civic duties' to censure. This seems to assume that 'citizens' as such stand in the kind of relationship to each other that makes effective communication leading to moral reform a possibility. Yet empirically-informed arguments suggest that moralising about crime is best left to those close to the offender both in personal relationship and in terms of peer group. ${ }^{40}$ This is not only because those who know and can relate to the individual are, generally speaking, better able put their crimes in context and thus to intervene in ways more likely to resonate with offenders, but also

\footnotetext{
${ }^{40}$ Braithwaite, J. Crime, Shame, and Reintegration. Cambridge University Press, 1989.
} 
because offenders are more likely to respond to those they consider peers, allies or close associates, whose opinion they care about and whose acceptance and approval they are motivated to secure. ${ }^{41}$ Somewhat paradoxically, those close enough to an offender to engage in the right kind of communication with them would not typically need labels to find out about their criminality. The label is for everyone else. Yet it is 'everyone else' who is least well-placed to communicate censure in the right way.

Even if it were possible to give citizens instantaneous detailed knowledge of those labelled and the crimes they have committed, asserting a universal civic duty to punish seems excessively burdensome. For many of us, faced with the presence of individuals guilty of serious crimes, it would require significant effort merely to control one's emotional reactions to the label, to 'keep calm and carry on', let alone to engage the individual concerned in rational persuasion to reform. People may understandably fear those with a history of violent crime or abusive behaviour, especially as they would not know how such individuals might react to public censure. Indeed it would be difficult to know how to react even to less disturbing breaches of the law, because partly because of the inevitable awkwardness that would come from engaging strangers or people we hardly know in discussion that is deeply personal, concerning as it does the state of their moral conscience. It seems unreasonable to insist that people nevertheless must engage directly with such individuals on the subject of their crimes. Yet making such engagement an imperfect duty (i.e. something we must sometimes do and to some extent but not necessarily in every possible case to the fullest extent possible ${ }^{42}$ ) risks entrusting punishment for some very difficult crimes to the eager few, who may have additional, extraneous motivations for helping individuals to reform. ${ }^{43}$

\footnotetext{
${ }^{41}$ This need not contradict claims made on p.13 above about the advantages of leaving censure to an authority that is accountable democratically, such as the judiciary, for two reasons. First, because the judiciary will typically have been given a great deal of information about both the specific incidents under consideration and the individual accused, and so will still be better placed than 'citizens' to deliver appropriate censure. Second, because the fact that a criminal's peers might be best placed to deliver effective censure does not mean that they will generally be motivated to do so such that they could be relied upon to fulfill the function of a punishing authority.

${ }^{42}$ For an account of Kant's distinction between perfect and imperfect duties see Hill, Thomas E., Dignity and Practical Reason in Kant's Moral Theory. Ithaca: Cornell U.P (1992).

${ }^{43}$ It is not difficult to imagine some religious groups seizing the opportunity presented by a badging system to acquire new souls and coming to dominate the field of censure.
} 
Even if people were not required to respond punitively to knowledge of criminality, the mere fact that such knowledge is forced upon them creates a de-facto requirement to know, and this by itself seems problematic, at least for those amongst us who would genuinely prefer not to know. Why might some people reasonably prefer not to be alerted to the criminality of others? One reason might be that giving criminality such prominence in public risks destabilising widely valued conventions of concealment that constitute what Thomas Nagel has called 'one of the conditions of civilisation' ${ }^{44}$ Non-exposure of criminal history in everyday interpersonal interactions, combined with the knowledge that criminal justice is being done elsewhere, on our behalf, helps to maintain the kind of civilised atmosphere that enables people to go about their business with others in an ordered and peaceful manner. The prominence of a criminal badge would make an individual's criminal history impossible to conceal or ignore. Imagine being regularly faced in one's daily interactions at the supermarket, on public transport, at the park with one's children - with murderers, rapists, child abusers, wifebeaters, terrorists, robbers, pimps, drug dealers, thieves and dangerous drivers. Of course, we are all faced regularly with such people today, but the fact that we - generally speaking - don't know who among us they are, enables civilised interaction to take place. ${ }^{45}$

Both the issue of overdemandingness and the previous concern about people's natural awkwardness and/or fear might be addressed by producing a script, which both offender and censurer could learn and recite, in a kind of ritual of censure and repentance. This could alleviate some of the uncertainty and fear on both sides and facilitate communication. But ritualistic exchanges can all too often become mechanical and easy to enact without genuine personal conviction. Even an optional script risks substituting meaningful communication with empty phrases.

To sum up, in this section I have argued that public criminal labelling as punishment is difficult to justify on communicative grounds, even in a society in which most people were genuinely

\footnotetext{
${ }^{44}$ Nagel, 'Concealment and Exposure' Philosophy and Public Affairs, 27(1), 1998, p. 3.

45 'The point of polite formulae and broad abstentions from expression is to leave a great range of potentially disruptive material unacknowledged and therefore out of play.' Nagel, Ibid. p. 1. Here Nagel is discussing social conventions of privacy, but his points are relevant to people's criminal histories and judged propensities.
} 
committed to the communicative account of punishment. The reasons for this, which include concerns about unfairness, disproportionality, and the challenges to effective communication faced by even well-meaning individuals, all stem from the fact that labellingas-punishment transfers some of the right and duty to punish from authoritative institutions to citizens. Such a move seems to hold most potential if implemented in small, tight-knit, morally homogenous communities. In such communities, people already know each other well, which means that awkwardness and fear are reduced and crimes can be put into context. People who abuse their right to punish are easier to hold accountable morally for abusive censure, as this is likely to be witnessed by associates. But it seems unlikely to be successful in mass societies populated by disconnected and sometimes mutually suspicious groups and individuals that often do not relate to each other. Against this background, any faith in 'citizens' as such to take on this reformative role seems misplaced. An alternative is presented by current efforts in the field of restorative justice, which aim to connect offenders with specially trained professionals and therapists who can broker such communication and engagement as well as guide and nurture it once it is in place. But restorative efforts do not involve labelling individuals or publicising their criminality to society in general.

Towards the beginning of this paper, I wrote that the considerations put forward in relation to Duffs idea of criminal badging can help us to think more clearly about the potential for contemporary criminal labelling practices to be justified as punishment. But, it might be argued, all the points I have made thus far against the view that labelling may be justified as punishment on communicative grounds - points about the likely disproportionality, excessive demands on individuals to communicate disapproval, barriers to reconciliation and reintegration, and unfairness - have all been discussed in relation to criminal labels that are used in place of other kinds of punishment; that attach physically to the offender, like clothing or a badge; and that are therefore extremely conspicuous in a way that makes them both dominant in relation to other characteristics of the offender and very difficult for others to ignore. Many contemporary criminal labelling practices do not involve such conspicuous marking out, many are limited to a certain place and time, 
and most take place alongside other, formal sanctions, such as community service.

It is true that the stigmatising potential of mugshots on posters, high-visibility work vests, or mentions on a police-hosted website or in the local paper pales in comparison to that promised by criminal badges. But this gives us no reason to think they are any easier to justify as punishment on communicative grounds. ${ }^{46}$ And in any case, current differences between readily available criminal labels, such as listings in online databases or on police websites, and highly conspicuous labels such as Duff's criminal badges may shrink and even disappear as technological developments collate and present information about people to us automatically. For example, it is not far-fetched to imagine that at some point in the near future many people will use connected wearable devices equipped with powerful facial recognition technology that could be set to automatically provide summaries of online information about everyone the wearer comes across, in real time. If that occurs, then criminal labels that can currently be revealed by an Internet search will become far more conspicuous. ${ }^{47}$

\section{PUBLIC CRIMINAL LABELLING AS A DETERRENT TO CRIME}

But perhaps the justification for labelling-as-added punishment is to be found in its deterrence or crime-reduction function, rather than its potential as a means of communication. It is often taken to be obviously true that the prospect of the publicity of criminalisation induces fear and shame and thereby deters would-be criminals. ${ }^{48}$ As Hart observed: '[A constitution maker] will be likely to regard the desire of the ordinary man to avoid the moral condemnation of his community . . . as a powerful factor influencing human behavior which can scarcely with safety be dispensed with. ${ }^{49}$ And deterrence has in practice motivated the use of criminal labels by police to publicly name and shame offenders. For example, deterrence both of offenders and

\footnotetext{
${ }^{46}$ As far as I am aware, Duff himself does not attempt to justify such actual examples of public labelling on punitive grounds. Where he does defend publicity in criminal justice, this is primarily in terms of the importance of public participation in criminal justice processes, though considerations of transparency and deterrence are also given weight (Duff 1991, p. 148).

47 Tunick, 'Privacy and Punishment', Social Theory and Practice, 39(4), 2013: 643-668.

${ }^{48}$ Arneson, R. 'Shame, stigma and disgust in the decent society', Journal of Ethics, 2007; Kahan DM (2006) 'What's really wrong with shaming sanctions' Texas Law Review 84(7), pp. 2075-2097.

${ }^{49}$ Hart, HM. 'The aims of the criminal law', Law and Contemporary Problems, 23(3), 1958: 401-441, p. 409.
} 
would-be offenders accounted for three of the four objectives listed by Essex police in support of their proposed offender-naming scheme, under which they planned to display posters bearing a photograph of a selected offender, their name, the nature of their offence, the sentence and the words 'If you come to Brentwood to commit crime, expect to do the time. ${ }^{50}$ The question of whether public criminal labelling deters is an empirical one and in this section I draw attention to some recent research on the topic that suggests this approach to justifying labelling as punishment is unpromising.

Labelling theory is a strand of criminological research that analyses the impact on recidivism and delinquency of criminal labelling. Labelling theorists typically define labelling as the application of a public criminal record. In a 2007 paper, Chiricos et al. examined, in a US context, the relative impact on recidivism of felony convictions that are accompanied by a publicly accessible criminal record and those in which the judge restricts the publicity of the record. Individuals whose conviction did not result in criminal labelling lost no civil rights (to vote etc.) and could legitimately fail to declare the conviction on employment applications and elsewhere. Analysis of reconviction data for 95,919 men and women supported the conclusion that those formally labelled are significantly more likely to reoffend in two years than those who are not. ${ }^{51}$ Longitudinal studies have produced similar findings. ${ }^{52}$

The explanations given for how and why labelling increases recidivism centre on the difficulty of desisting from crime when, as for example is often the case in the USA and Europe, one's criminal label prevents or obstructs one finding a decent job. ${ }^{53}$ In the USA, it can also prevent one renting accommodation, or qualifying for loans or housing assistance. ${ }^{54}$ As Jacobs puts it ' $[t]$ he criminal justice sys-

\footnotetext{
${ }^{50}$ See Ellis v. The Chief Constable of Essex Police [2003], EWHC 1321.

${ }^{51}$ Chiricos, Barrick, Bales and Bontrager, 'The labeling of convicted felons and its consequences for recidivism', Criminology, 45(3), 2007.

${ }^{52}$ Bernburg, Krohn \& Rivera 'Official labelling, criminal embeddedness, and subsequent delinquency: a longitudinal test of labelling theory' in Journal of Research in Crime and Delinquency, 43(1), 2006: pp. 67-88.

${ }^{53}$ Criminal record data is made available to employers in the UK and EU countries and those with a criminal record are in many countries barred from a wide range of public sector and licensed positions. (Larrauri-Pijoan 2014).

${ }^{54}$ Pager, D. Marked: Race, Crime, and Finding Work in an Era of Mass Incarceration University of Chiese Press, 2009; Vallas and Dietrich, 'Minor crimes should not lead to a life-sentence', Newsweek, 12/3/14; Maruna, S. 'Judicial Rehabilitation and the 'Clean Bill of Health' in Criminal Justice', European Journal of Probation, 3(1), (2011): 97-117.
} 
tem feeds on itself. The more people who are arrested, prosecuted, convicted and especially incarcerated, the larger is the criminally stigmatized underclass screened out of legitimate opportunities, ${ }^{55}$ If this is correct, then it is likely that limiting the application of criminal labels reduces both the harms of stigmatisation to offenders and the harm to society of increased crime. There are also of course reasons of social justice to avoid measures that contribute to the creation of an entrenched underclass, of any sort.

While the results of these studies are fascinating, there are limitations to their weight as evidence for the claim that labelling as added punishment does not have significant crime-reduction effects, via deterrence. These stem from two features of the research. The first is that it compares rates of recidivism for offenders who have been incarcerated and labelled with those for offenders who have been neither incarcerated nor labelled. That makes it difficult to isolate the effects of labelling from the effects of incarceration. This is a real challenge, given that a range of studies appear to show that longer periods of incarceration are correlated with higher rates of recidivism. $^{56}$

The second is that it does not attempt to measure deterrence as such, just recidivism, which is only one aspect of deterrence. This is not a problem if the ultimate aim of deterrence is to reduce the overall number of crimes committed. Most crimes are committed by the same people; therefore if a measure reduces recidivism by deterring offenders, it will reduce overall crime significantly. But if the aim of deterrence is both to reduce the overall number of crimes and to reduce the overall number of people criminalised, then deterrence measures should be targeted towards those who would otherwise commit crime as well as those who already have committed a crime. Because it only reports rates of recidivism, the research cited above cannot tell us whether labelling criminals deters would-be criminals.

Despite these caveats, the research does suggest a positive impact on recidivism of labelling that is difficult to discount. In the light of

\footnotetext{
${ }^{55}$ Jacobs, J. Mass incarceration and the proliferation of criminal records' in University of St Thomas Law Journal 3(3), 2006: 387.

${ }^{56}$ Cullen, F and Jonson C, 'Labelling Theory and Correctional Rehabilitation: Beyond Unanticipated Consequences' in Labelling Theory: Empirical Tests, Farrington and Murray (Eds.) New Jersey: Transaction, (2014).
} 
this, any attempt to justify public labelling of criminals in terms of deterrence would need to indicate convincingly that it reduced firsttime offending by more than it aggravated recidivism. This has yet to be done. What all this suggests is that if punishment is justified in virtue of its deterrence or crime-reduction effects, then adding public criminal labelling to other sanctions is unlikely to be justified as punishment. This conclusion is relevant both to the discretionary labelling intentionally inflicted by judges (as in the case of the sandwich-board wearing Hubacek) and to that legislated by elected representatives deciding whether public labelling should feature in or accompany any new or existing punishments on the books.

\section{CONCLUSION}

Towards the start of this paper I indicated that one of the motivations for writing it was to interrogate the claim that labelling is an appropriate response to a criminal conviction, but a violation of the presumption of innocence in the absence of such a conviction. The arguments put forward here should not be taken to suggest that criminal guilt or innocence makes no difference to the wrongness of inflicting a criminal label. On the contrary, when an innocent person is labeled a criminal they are wronged severely and their rights are violated, because the mere fact of their being labeled undeservingly is an injustice, prior to any consideration of the proportionality or fairness of the publicity given to the label. Being labeled inaccurately as a criminal is insulting and it is a violation of the presumption of innocence. It also exposes the individual in question to the risk of undeserved harms resulting from criminal stigmatization. But labelling an innocent individual as a criminal is wrong in principle and not only in virtue of such potential harms.

In contrast, labelling an individual accurately as criminal is neither insulting nor a violation of their presumption of innocence, nor indeed is it unjustified in principle. Rather, nothing that has been argued here rules out the possibility that (good enough) evidence of criminality makes the act of labelling morally permissible. But the inevitable stigmatizing effects of public labelling make a robust justification necessary. If what has been argued here is convincing, then such a justification cannot be constructed by appeal to either the communicative or the deterrence functions of punishment. 


\section{ACKNOWLEDGMENTS}

This research was funded by the European Commission under the Seventh Framework Programme project 'SURVEILLE: surveillance, ethics, legal limitations, and efficiency' (www.surveille.eu), [Grant No. 284725]. Thanks to participants in the CELPA seminar at the University of Warwick who gave me helpful comments on this paper, especially to Matthew Clayton, Keith Hyams and Chris Nathan. Thanks are also due to the anonymous reviewers of Law and Philosophy for their suggestions, which helped improve the paper.

\section{OPEN ACCESS}

This article is distributed under the terms of the Creative Commons Attribution 4.0 International License (http:/ / creativecommons.org/licenses/ by/4.0/), which permits unrestricted use, distribution, and reproduction in any medium, provided you give appropriate credit to the original author(s) and the source, provide a link to the Creative Commons license, and indicate if changes were made.

Interdisciplinary Ethics Research Group,

Department of Politics and International Studies,

University of Warwick, Coventry, UK

E-mail:k.hadjimatheou@warwick.ac.uk 